\title{
NUEVOS MIGRANTES ARGENTINOS EN BARCELONA: UNA INDAGACIÓN ETNOGRÁFICA ALREDEDOR DE LOS PROCESOS DE INTEGRACIÓN E INSERCIÓN SOCIOLABORAL
}

\author{
ALEJANDRO GOLDBERG \\ Transmigrared
}

\section{RESUMEN}

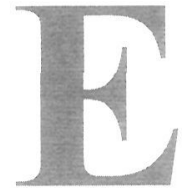

n lo que respecta al planteamiento teórico-metodológico-conceptual para abordar la nueva migración de sudamericanos a Europa, es importante tener en cuenta, como primera cuestión, que se trata de un fenómeno histórico-sociocultural humano (las migraciones internacionales) que adquiere manifestaciones concretas en la era contemporánea de la globalización. Lo anterior implicará necesariamente un permanente ejercicio de análisis dialéctico: particularizar el tipo de migración que se trata con la especificidad de los diferentes contextos -histórico, geográfico, global, social, político y cultural-, tanto de origen como de destino, en los que se desarrolla el fenómeno.

Palabras clave: causas de la migración, mercado de trabajo, Argentina, España.

\section{INTRODUCCIÓN. UNA PERSPECTIVA HISTÓRICA-SOCIO- CULTURAL-TRANSNACIONAL PARA EL ABORDAJE DE LOS PROCESOS MIGRATORIOS}

Teniendo en cuenta tanto la multiplicidad como la complejidad de factores que intenten explicar ¿por qué la gente migra? -para el caso del que se trata, el porqué migran personas a España, $y$, más concretamente, por qué migran los argentinos)- de modo general, se puede ver como, en todo proceso migratorio, se dio siempre, en mayor o menor medida, un movimiento centrípeto o de atracción -el pull-y otro centrífugo o de expulsión - el push-, de un sitio a otro. El modelo del push and pull ha sido planteado por Ravenstein (1885) y aún tiene vigencia en un mundo globalizado, quizá más como factor interactuante que como modelo en sí (Goldberg, 2004b: 28).

Los ejemplos históricos abundan y son variados en cuanto a fenómenos que los originaron, causas que los encendieron y factores que los determinaron. En 
términos generales, guerras, epidemias, desastres naturales, crisis económicas, conflictos étnico-políticos, etc. de un lado-push-, y paz, bienestar, trabajo, etc. del otro - pull-. Los más de 80 millones de europeos emigrados en los últimos dos siglos -de los cuales, algo más de 9 millones eran españoles con destino preferentemente a América Latina-, por un lado, y los aproximadamente 20 millones de personas que llegaron a Europa provenientes de América, Africa y países del Commonwealth, por el otro, representan ejemplos de lo referido.

Los países receptores desde los cuales proviene el movimiento centrípeto o de atracción - el pull-, que, de alguna manera, "llama" a la inmigración, necesitan, en mayor o menor medida, mano de obra o fuerza de trabajo para algunas de las ramas productivas de sus economías. La reconstrucción europea de la posguerra que atrajo africanos y asiáticos de las ex-colonias, el desarrollo económico de los países europeos más industrializados que atrajo a trabajadores españoles, la expansión de la economía estadounidense en la que participaron trabajadores de todas partes del planeta, la agricultura española del siglo XXI...

Paralelamente, muchos de esos casos muestran también la necesidad por parte de los países receptores de esa mano de obra de aumentar su población, ya sea total o económicamente activa. La Argentina de fines del siglo XIX y principios del $\mathrm{XX}, \mathrm{y}$, un siglo más tarde, los dos países europeos con las tasas de natalidad más bajas del planeta (Italia y España) constituyen ejemplos históricos de lo referido.

De modo que el sistema capitalista mundial, en sus distintas fases de desarrollo, ha generado e impulsado distintos procesos migratorios según su conveniencia. Migraciones internas del campo a las ciudades, migraciones transnacionales, migraciones interurbanas, migraciones de mano de obra no calificada $\mathrm{y}$, por último, migraciones de mano de obra altamente calificada desde la periferia hacia el centro (o desde el tercer mundo hacia el primero)', sin haber invertido una moneda en su formación. Mano de obra que, por su situación legal y social, vende su fuerza de trabajo en los países de destino por un salario menor que el de los autóctonos. Se trata, además, de fuerza de trabajo barata en su mantenimiento, funcional a sus economías y a sus planificaciones poblacionales.

Desde un punto de vista estrictamente económico, el fenómeno de las migraciones actuales nos remite al proceso de reacomodo de la fuerza de trabajo en el nuevo mercado mundial del trabajo globalizado ${ }^{2}$. Se trata de una nueva

1 Considero válida y vigente la distinción conceptual en la que se establece una dicotomía entre paises "industrializados-desarrollados-centrales", por un lado, y paises "no industrializados-en vías de desarrollo-periféricos", por el otro. En cambio, no creo idónea la clasificación que frecuentemente se hace entre países "ricos" y países "pobres". Tomemos los casos de Argentina o Brasil, paises ambos ricos en recursos naturales variados (mucho más ricos que Suiza o Austria, por ejemplo), pero cuyo usufructo se realiza a través de las élites de poder locales en función de intereses foráneos, ya sea de otros países como de empresas multinacionales, debido al carácter dependiente o neocolonial de sus gobiernos. En este sentido, y en contraposición a las nuevas metáforas pregonadas desde el discurso neoliberal hegemónico, se rescatan categorías analíticas que mantienen vigentes García Canclini y otros, como las de primer/tercer mundo, centro/periferia, etc. (Goldberg y Pedone, 1999).

2 La globalización constituye la etapa actual del desarrollo capitalista mundial, que en lo económico implica la expansión del mercado, la hegemonia del capital financiero sobre el productivo y una guerra entre las doscientas empresas transnacionales más poderosas del planeta por conquistar nuevos mercados y territorios. 
forma de acumulación flexible del capital, en un contexto post-fordista, en el cual los mercados de empleo estarían cada vez más determinados por los flujos migratorios y éstos, a su vez, estarían determinados por la demanda de mano de obra de los países receptores ${ }^{3}$.

Tenemos así que es sobre todo a principios de la década de 1990 cuando se constata globalmente un aumento de los movimientos migratorios, fundamentalmente desde los países periféricos hacia los países centrales. La situación estructural de muchos países periféricos está caracterizada fundamentalmente por la desigualdad en la distribución de la renta, una mayoría de la población joven, buena parte de la población económicamente activa sin empleo o subempleada y otro alto porcentaje de la población con las necesidades básicas insatisfechas.

En cuanto a los factores que impulsan los movimientos migratorios -el push-, como el de norteafricanos y sudamericanos a España, pueden mencionarse la proximidad geográfica y las relaciones coloniales o lazos históricos previos, los contactos frecuentes o el conocimiento del idioma y de las redes sociales que funcionan desde hace tiempo en varios países europeos. Sin embargo, estas características que son evidentes desde siempre en los movimientos de población, en el contexto de la globalización, se han incentivado debido a la información constante por parte de los medios de comunicación masivos, el abaratamiento de los medios de transporte y el funcionamiento cada vez más dinámico de las mafias de tráfico ilegal de inmigrantes. Martínez Veiga (1997: 229) agrega una variable importante que, sumada a las expuestas, es necesario tener en cuenta para abordar casos como el de los nuevos migrantes argentinos, referido en este trabajo: la correlación existente entre inversiones españolas en determinados países con altas tasas de emigración hacia el país inversor, tal como sucede con Marruecos y algunos países de América Latina (Colombia, Chile, México, Argentina, Ecuador, etc.). Para este autor, la inversión extranjera en los países emisores de mano de obra actuaría como un acicate para la emigración ${ }^{4}$.

Los movimientos poblacionales presentes en los procesos migratorios actuales se conciben dentro de una estructura dinámica conformadora de un

La ideologia que sustenta este proceso es el neoliberalismo, el cual intenta impregnar de manera global y uniforme todas las esferas de la vida social, política y cultural de las sociedades actuales. (Subcomandante insurgente Marcos, 1996). Es la globalización del poderio hegemónico de Estados Unidos como gran potencia bélica, financiera, cultural y comunicacional.

3 El "nuevo orden mundial" organiza el flujo de fuerza de trabajo, especializado y no, hacia donde lo necesita. Muchas de las políticas internacionales para los distintos países, en los últimos años (incluyendo como parte de esas "políticas" guerras y conflictos étnico-regionales, hiperinflación. altos indices de desocupación, dolarización de las economías, etc.) se ajustan a este análisis.

4 Después de Estados Unidos, España es el país que más intereses económicos posee en Argentina, al igual que en otros países del continente americano, como Chile y México, a través de la compra de empresas públicas privatizadas en sectores estratégicos de la economía de "nuestros" paises. No es casualidad que a partir de concesiones como la de Telefónica (1990) y otras empresas de capital español en Argentina, pueda ubicarse el "boom" de crecimiento económico de España, generado justamente con las superganancias que se obtienen en la "(neo) ex colonia". En ese sentido, esta suerte (o mala suerte) de nueva política "virreinal" puede constatarse en la fuerte presencia del Banco Santander Central Hispano (BSCH) y el Banco Bilbao Vizcaya (BBV) en el sistema bancario financiero; Telefónica en comunicaciones; Repsol (que compró la ex argentina YPF), Endessa e lberdrola en explotación, generación y distribución de energía; Iberia primero y Marsans después (Aerolíneas Argentinas), Indra o Aguas de Barcelona, para mencionar algunos casos. Tiembla la Bolsa de Buenos Aires, tiembla la de Chile y la de México... y tiembla entonces la de Madrid. 
"espacio migratorio". Se trata de un espacio "extenso, continuo y complejo, que trasciende fronteras formales, sean éstas políticas, geográficas, lingüísticas, coloniales, religiosas o residenciales" (Kaplan, coord., 1996: 1). Siguiendo a Parramón (1996: 19), el término de "campo migratorio" refiere a esta estructuración del espacio, concebido como un "sistema espacial organizado en torno a los flujos migratorios, y en el que se establecen vínculos complejos entre los polos", confirgurándose de esta manera una forma de espacio relacional. La perspectiva transnacionalista de las migraciones, sostenida por estos autores, concibe a la migración transcontinental o transnacional constituida como una institución en sí misma, donde los determinantes individuales y los factores de tipo estructural se entremezclan con elementos de orden individual-familiar-comunitario.

Incorporar al análisis holístico variables demográficas, espaciales, culturales, sociales, económicas, políticas e ideológicas permite identificar, describir e interpretar algunos de los elementos fundamentales de los procesos migratorios, a saber: las condiciones de existencia que determinan el contexto sociopolítico y, enmarcadas en ellas, las relaciones y estrategias de adaptación generadas por los sujetos, tanto en la sociedad de origen como en la de destino; los actores sociales que participan en las diferentes etapas del proceso; etc.

De esta manera, el conocimiento antropológico de los diferentes procesos permite conocer las características comunes y las condiciones más generales, de manera que el énfasis en alguno de sus aspectos no suponga desprenderlo de los contextos en los que se producen y desenvuelven (Kaplan, ob. cit.). De ahí que la acción de comprender, aquí, signifique analizar el fenómeno desde su complejidad sin extraerlo de su contexto histórico-social.

A nivel general, este trabajo busca realizar un aporte al conocimiento de la nueva migración de argentinos a España, destacando el desafío metodológicoconceptual que ha supuesto abordar el análisis de un fenómeno internacional complejo - tratado por ciertos discursos locales como "problema" (social, cultural, religioso, etc.)-, siendo un investigador extranjero, no perteneciente a esa sociedad. De modo que mi posición en el mismo ha estado marcada desde el inicio por una particularidad: aunque me he encontrado inserto durante un periodo de seis años residiendo en la sociedad/cultura catalana-española-europea, no pertenezco a la misma, sino que provengo de otra distinta. En esto, para buena parte de los autóctonos (y teniendo en cuenta las leyes migratorias vigentes) he sido un "extranjero" al igual que otras personas inmigrantes; puntualmente "sudaca" y no "moro", por ejemplo, y específicamente argentino y no ecuatoriano. De modo que podría decirse que soy parte del "problema" y por eso me atañe en su totalidad, lo cual ha supuesto desde un comienzo asumir la necesidad del ejercicio metodológico del distanciamiento.

J. P. Sartre, en su Crítica de la razón dialéctica, afirmaba: "La única teoría del conocimiento que puede ser válida hoy en día es la que se funda sobre esta verdad de la microfisica: el experimentador forma parte del sistema experimental" (citado en Feinmann, 1998: 173). Para ejemplificarlo, ningún inmigrante extranjero que estudie la inmigración en España (el experimentador) puede no ser atrapado por el sistema experimental. 
Del lado opuesto a planteamientos metodológicos positivistas como los de Novick (2004: 1), quien asegura que "El hecho de estar inmerso en la misma realidad que se pretende observar, analizar y explicar condiciona a priori los posibles hallazgos y aciertos del trabajo", Holloway (2002: 98) escribe: "En la idea burguesa de ciencia (...) el distanciamiento del individuo respecto de la comunidad se considera una virtud (...) El cientifico ideal seria un observador ubicado en la luna, desde donde sería capaz de analizar la sociedad con verdadera objetividad (...) Según esta manera de pensar, ciencia y objetividad se consideran sinónimos (...) La objetividad significa suprimir todo lo posible nuestra subjetividad".

En ese sentido, mi experiencia como investigador in situ, como parte del hecho de vivir en Barcelona desde hace seis años, me ha permitido obtener información de calidad -aplicando técnicas cualitativas propias de la metodología etnográfica desde una perspectiva emic - que de otra manera hubiera resultado imposible de lograr. La crítica, de esta forma, la realizo como parte de mi objeto, con el cual formo una sola totalidad problemática: no puedo no-ser parte de ella $y$, a la vez, es esta pertenencia la que me permite comprenderla.

A través de distintas técnicas y procedimientos -entre los que destacan la observación participante y las entrevistas en profundidad, aplicando la técnica de historias de vida 5 (para el caso, "trayectorias migratorias")-, un estudio etnográfico puede abordar los procesos migratorios internacionales contemporáneos mediante un enfoque dinámico que intenta recuperar las representaciones y las prácticas, los saberes y las experiencias, resignificados por los sujetos a partir de sus historias de vida, de su identidad sociocultural y de sus condiciones de existencia en la sociedad receptora. Desde una perspectiva de análisis sociocultural del fenómeno es importante rescatar los hábitos, pautas de comportamiento, actitudes, costumbres y rasgos de la cultura y la sociedad de origen que se mantienen, son resignificados o se transforman y modifican entre los migrantes, y que determinarán en cierta forma el grado de adaptación, integración o exclusión en el contexto sociocultural de la sociedad de destino.

Martínez Veiga (1997: 12) se refiere a ello cuando afirma que en el caso del estudio de la inmigración es fundamental escuchar la diversidad de interpretaciones que, tanto los inmigrantes como los autóctonos o nativos, llevan a cabo. En opinión del autor, esto permite confrontarlas con las prácticas de los actores sociales en un contexto determinado, otorgando a la observación participante así una seguridad y anclaje particulares en el abordaje de los fenómenos empíricos.

En consecuencia, como investigador extranjero en Europa, abordo la problemática de los desplazamientos de población con su carga de vivencia cotidiana, la cual, en reiteradas ocasiones, el discurso eurocéntrico obvia por completo.

5 Al utilizar historias o trayectorias de vida como estrategias de investigación, uno de los objetivos que se persigue es el de analizar la manera en que un sujeto mantiene y/o modifica su identidad en el proceso de migración, abordando la relación entre sujeto e identidad, la cual incluye la esfera del espacio privado. La reconstrucción de las trayectorias de vida de los actores resulta eficaz para recabar información sobre la realidad del grupo analizada, resultando un recurso idóneo por la información que otorgan del pasado, y, sobre todo, por la importancia de éste en el análisis de la realidad de los sujetos de estudio en la sociedad de destino. 
Por último, vale apuntar el hecho de que el fenómeno de estudio que se propone abordar en este trabajo tiene un carácter nuevo, actual y emergente, con importantes alcances y complejas connotaciones históricas, politicas y socioculturales, sobre todo para Argentina. Al mismo tiempo, se pretende destacar en este planteamiento algunas variables relativas a la especificidad que tiene el fenómeno de la nueva migración argentina dentro del contexto referido. De modo que, desde el punto de vista del conocimiento, lo anterior lo convierte en un interesante y a la vez necesario desafio. ${ }^{6}$

\section{MERCADO DE TRABAJO Y DISTRIBUCIÓN DE LA POBRE- ZA EN LA ARGENTINA DE FIN DE SIGLO}

Este trabajo refiere a una investigación en curso sobre el nuevo flujo de migrantes argentinos a España, la cual he comenzado a desarrollar a partir de octubre de 2003 en adelante entre las ciudades de Barcelona y Buenos Aires. A lo anterior, se le agrega la recopilación bibliográfica y el trabajo de campo realizado en Génova, Italia, entre los meses de mayo y julio de 2004, como becario-investigador de TransMigraRed.

Referirse en términos de "nuevo" flujo de migrantes argentinos supone en este caso reconocer la existencia de importantes flujos migratorios anteriores de argentinos a Europa/España/Barcelona. Concretamente, en lo que concierne a los movimientos migratorios de argentinos a España, a grandes rasgos, es posible distinguir tres etapas, vinculadas, a su vez, con determinados factores centrífugos o de expulsión -el push-interactuando en cada fase:

1) 1976-1983 (dictadura militar).

2) 1989-1992 ("hiperinflación alfonsinista-menemismo temprano").

3) Diciembre de 2001 hasta nuestros días (quiebre del sistema financiero, devaluación del peso, corralito, cacerolazos, profundización de la pobreza y la desocupación hasta niveles nunca antes conocidos en la historia de nuestro país, extensión de la delincuencia y aumento de la violencia en los delitos).

Dentro de esta última etapa, se encuentran los sujetos de estudio de esta investigación: jóvenes argentinos provenientes de las principales ciudades del país (Buenos Aires, Córdoba, Rosario, Mendoza, Mar del Plata, La Plata, etc.) que han arribado masivamente a distintas ciudades de España (Barcelona, Madrid, Valencia, etc.) luego de la crisis de diciembre de 2001, principalmente, durante todo el año 2002 (ver tabla 1) y, en menor medida, en 2003. En una primera aproximación, podría decirse que, a diferencia de los sujetos de la primera etapa (1976-1983), se trata de una migración cuya motivación principal es la individual-económica-profesional. En este marco, España e Italia, los principales países emisores de migrantes a la Argentina de principios del siglo XX, reciben la joven y relativamente calificada migración argentina (fundamentalmente España y, en menor medida, Italia) tras sólo dos o tres generaciones.

6 Es importante remarcar que no existen hasta el momento trabajos de investigación realizados desde una perspectiva cualitativa sobre el tema del que se trata. En esta presentación, y por razones de espacio, recortaremos el análisis de lo que se reficre estrictamente al ámbito del mercado de trabajo. 
En términos numéricos, según datos de la Dirección Nacional de Migraciones, hasta marzo de 2003, se habían ido del país, sin regresar, alrededor de 260.000 personas (sólo en 2002 se fueron 90.000). Para Lelio Mármora, director de la Maestría en Políticas de Migraciones Internacionales de la UBA, y en la actualidad también del INDEC, el proceso migratorio del que se trata se convirtió en un fenómeno sociocultural determinado tanto por la crisis y la situación económica como por la frustración en las expectativas de un sector joven de la población, que creció y se formó en la Argentina de la década de 1990 (Fuente: Página 12, abril 2003, edición digital).

Esta apreciación es fundamental, ya que, de alguna manera, sugiere cuáles son los rasgos principales del conjunto social protagonista del proceso migratorio, así como las motivaciones centrales para haber emigrado.

Una muestra potencial de esos jóvenes que crecieron y se formaron en la década de 1990 aparece en el estudio realizado por Cacopardo (1992), enfocado en aquéllos de origen italiano, que la autora designa "italoargentinos". Para esas fechas, y situada en el contexto de los inicios de la década de 1990 en Argentina, Cacopardo (ob. cit.: 494) planteaba:

“(...) las personas jóvenes aparecen como la subpoblación más expuesta a una posible emigración (...) En la medida que la etapa de capacitación, ya sea por la via de la educación o por la experiencia laboral, no garantiza una inserción en el mercado de trabajo que permita acceder a un adecuado nivel de vida, los jóvenes son llevados a cuestionar su permanencia en esta sociedad". Y concluía: "En la medida que las expectativas no se satisfagan y los jóvenes que han apostado a una carrera, a un perfeccionamiento profesional y técnico, continuen sin poder ubicarse, sin encontrar gratificaciones laborales y económicas, sin sentir que se premia el esfuerzo personal, es probable que retomen sus latentes proyectos de emigración, y que en forma empírica $y$ alejada de toda fantasia, desarrollen las estrategias necesarias para efectivizarlos".

Describiendo y analizando aspectos de la pasada década, puede decirse que el impresionante crecimiento de los indicadores de desempleo y pobreza son la expresión más visible del nuevo patrón distributivo desigual y excluyente instaurado en ella, a partir de la estricta imposición de las políticas derivadas del "Consenso de Washington"7. Al finalizar la década y el siglo, la Argentina ha pasado de conformar una sociedad con cierto grado de homogeneidad y estructuras de ingreso más equitativas, a otra donde predominan la desigualdad y la regresividad en la distribución del ingreso y la riqueza (Lo Vuolo, 2003).

Todos los estudios disponibles, aunn con discrepancias de enfoque, coinciden en destacar que, a partir de 1993, se registró un proceso de acelerado deterioro de la situación ocupacional en el país. Dentro de las tremendas secuelas socio-económicas de la llamada "Convertibilidad", tal vez la más sobresaliente haya sido la estampida de la desocupación: en 1991, los "desocupados abiertos" eran 700.000 personas; mientras que en 2001 habían escalado a 2,5

7 La expresión "Consenso de Washington" refiere a las políticas impuestas en los países del Tercer Mundo, derivadas de los organismos de crédito multilaterales con sede en dicha ciudad. 
millones, lo cual equivale a una tasa de crecimiento promedio anual cercana al $14 \%$. A estas cifras hay que sumar el llamado "desempleo oculto", esto es, las personas que dejan de ofrecer su trabajo en el mercado por estar desesperanzadas de conseguirlo: al final de 2001, en este grupo se registraban casi 345.000 personas que constituían el 2,5\% de la PEA total ${ }^{8}$ (Lo Vuolo, ob. cit.).

Al mismo tiempo, la Convertibilidad dejó un país con una distribución del ingreso más desigual que la heredada del período previo de la hiperinflación. La tendencia regresiva en la distribución del ingreso provocó un fuerte crecimiento de los indicadores de pobreza por nivel de ingreso. Tomando como referencia al Gran Buenos Aires, la Convertibilidad dejó como herencia un porcentaje de personas pobres por ingresos que escaló desde el 21,5\% en 1991 hasta el $35,4 \%$ de la población total en 2001. Con la maxidevaluación, en el año 2002 , este indicador saltó al $54,3 \%{ }^{9}$ (Lo Vuolo, ob. cit.).

Si bien es imposible sustraer a los sujetos de estudio de esta investigación del contexto general descrito más arriba, es importante igualmente hacer referencia al sector socioeconómico-ocupacional del cual no todos, pero sí en su mayoría, provienen: clase media/media-alta urbana con un trabajo calificado mal remunerado o sin experiencia laboral previa (sostenimiento económico de los padres).

Un elemento a destacar en base a las entrevistas realizadas como parte de una primera indagación etnográfica es que, entre los factores, motivos, causas y razones expresadas por los migrantes argentinos para emigrar (factores del push), sobresalen los de tipo económico-laboral.

De modo que, por el momento, se pueden realizar tres consideraciones:

1) Al igual que los migrantes españoles e italianos que arribaron al continente americano a principios del siglo pasado, sólo emigran los argentinos que pueden; pero, a diferencia de aquéllos, los nuevos migrantes argentinos que se instalan en Europa/España/Barcelona no son los más pobres en su sociedad de origen.

2) En lo que respecta a los motivos de orden económico-laboral, la mayoría de los argentinos que emigran no lo hacen por falta de trabajo en la sociedad de origen; por el contrario, el factor de más peso resulta ser la posibilidad de conseguir un trabajo, quizás de menor calificación, pero mejor remunerado, aprovechando sobre todo la diferencia del cambio favorable al euro en relación al peso argentino. Todo lo cual les permite, por un lado, aumentar notoriamente sus ingresos (aunque, al mismo tiempo, los gastos) y, por otro lado, tener la posibilidad de ahorrar dinero con vistas a un probable

8 Si esta gente se volcara al mercado de trabajo, ta tasa de desempleo abierto a esa fecha hubiese sido del $20,6 \%$, en lugar del $18 \%$.

9 Tan es así que hasta el Banco Mundial, en un estudio titulado "Hambre en Argentina", concluyó que durante 2002 , año posterior a la devaluación de 2001, uno de cada cinco hogares que sufrieron hambre en el país fueron "familias de clase media baja"; y que el $17,8 \%$ de los hogares argentinos convivió con el hambre tras la crisis. Por primera vez, el organismo reconoce la existencia de una fuerte relación entre la pobreza y el hambre, destacándose que "en la Argentina el hambre es fundamentalmente un problema de falta de ingresos". Esta situación -siempre según el documento- es la que habría llevado a una porción de familias de clase media baja a precipitarse transitoriamente en la pobreza, no pudiendo cubrir sus necesidades alimentarias más elementales. (Fuente: Página 12,7/9/04, edición digital). 
retorno en el corto plazo. En otras palabras, lo que se da es una maximización racional en términos costo-riesgo/beneficios.

3) A diferencia de proyectos migratorios como el de africanos (senegaleses, marroquíes, etc.) y de otros países sudamericanos (ecuatorianos, peruanos, etc.) a Europa/España/Barcelona, cuya sustancia reside en la diversificación económica familiar, en las cuales, en muchos casos, la misma familia es la que selecciona a los potenciales migrantes de acuerdo a sus potencialidades e invierte bienes y capitales en ellos, quienes irán devolviéndolo mediante el envío constante de remesas y la incorporación de familiares a las redes y cadenas migratorias, por el contrario, buena parte de los procesos migratorios de los nuevos migrantes argentinos son de carácter estrictamente individual.

\section{LA TRANSICIÓN ESPAÑOLA A LA GLOBALIZACIÓN NEO- LIBERAL: DE PAÍS DE EMIGRACIÓN A PAÍS DE INMIGRA- CIÓN}

Resulta indispensable subrayar el hecho de que la inmigración constituye un fenómeno relativamente reciente en España, que ha vivido en los últimos veinte años el progresivo cambio de status de "país de emigración" a "país de tránsito" y, luego, a "país de asentamiento". De esta manera, desde mediados de 1980, pero sobre todo a partir de 1990, la situación ha cambiado: España se ha convertido en un país de inmigración ${ }^{10}$ (Goldberg, 2004b: 30).

Entre los factores que explican la transformación de España en un país de inmigración, además de la importancia que actualmente adquiere su ubicación geopolítica, se encuentra el proceso de internacionalización de la economía y de crecimiento económico experimentado a partir de su incorporación a la Unión Europea (1986). Esto ha situado a España -en base a determinados indicadores macroestructurales- como uno de los países hispano-parlantes de mayor nivel de consumo del mundo y, al mismo tiempo, dentro de procesos de migraciones internacionales, aunque éstos se produzcan en menor medida en comparación con otros países europeos más industrializados" (Goldberg, ob.cit.: 31 ).

Asimismo, es interesante detenerse en algunas consideraciones demográficas, las cuales sugieren que a los países europeos les resulta imprescindible, no sólo mantener, sino aumentar considerablemente los flujos de las migraciones extranjeras -el pull-. Esto, para mantener los niveles actuales de prestaciones sociales básicas ligadas a la existencia del Estado del Bienestar (en proceso de retracción) y teniendo en cuenta sobre todo el envejecimiento de la población europea.

10 No obstante, resulta indispensable aclarar que hasta noviembre de 2003 el saldo migratorio seguia siendo favorable a España, con alrededor de dos millones de emigrantes españoles en el extranjero, frente a poco más del millón y medio de inmigrantes contabilizados por el Ministerio del Interior español. Recién en junio de 2004, la Administración reconoció que, por primera vez en su historia, España tenía más inmigrantes que emigrantes.

11 Vale recordar el hecho de que, hasta 1982, España todavía recibe ayuda de los organismos financieros internacionales en su carácter de "país en vías de desarrollo". 
Relacionado con lo anterior, en un informe de la división de población de la ONU (United Nations, 2000) se advertía a los países miembros de la UE que necesitaban unos 70 millones de trabajadores inmigrantes durante los próximos cincuenta años para mantener su crecimiento demográfico, y 44 millones hasta el 2050 para mantener el crecimiento económico y proteger las pensiones.

Para tener una aproximación empírica de la cuestión referida, y en base a datos del Instituto Nacional de Estadística (INE), en 2003, España poseía la tasa de natalidad más baja de la UE, después de Italia $-1,26$ hijos por mujer en edad fértil, siendo la media de la UE de 1,53-. Un dato por demás significativo, si se tienen en cuenta dos factores. Primeramente, el hecho de que sólo 20 años antes, cuando aún recibía ayuda económica de los organismos financieros internacionales, por su categoría de país "en vías de desarrollo", España era el segundo país con mayor tasa de natalidad en Europa: 2,2 frente al 1,8 de Europa. En segundo lugar, que en 2003 esta tasa aumentó debido al nacimiento de niños de madres extranjeras, los cuales constituyeron el 10\% del total. Es importante así remarcar el hecho de que actualmente España cumple con el perfil que caracteriza a las dinámicas demográficas actuales de la población europea occidental: aumento de la esperanza de vida al nacer, recepción de movimientos migratorios internacionales, descenso de la natalidad y envejecimiento de la población nativa (Goldberg, ob. cit.: 31-32).

Por último, según datos del Eurostat (2003), de los 1,9 millones de personas que aumentaron la población de la UE en 2003, 1,68 millones son extranjeros. Vale decir que, sin ellos, la población europea sólo se hubiera incrementado en 220.000 habitantes. La mayoría de estos inmigrantes se instaló en España (594.300 personas, la cifra más elevada de la UE, lo que supone un $35,3 \%$ del total).

¿Con qué condiciones socio-laborales se encuentran estos migrantes al llegar a España?

¿Cuál es el contexto en el que se producen los procesos de integración/exclusión a la sociedad de acogida?

¿Es lo mismo ser trabajador inmigrante en España que en otros países de la UE? Y, dentro de España, ¿son iguales las condiciones en Barcelona que en Almería?

¿Qué tipo de elementos interactúan en el contexto español actual para que un fenómeno histórico-socio-cultural humano como las migraciones, pueda llegar a convertirse en un "problema" en términos de la percepción social de la población autóctona (los españoles)?

¿Cómo impacta lo anterior en el ámbito de las relaciones interculturales donde se generan las interacciones entre los sujetos? ¿De qué manera influye esto en sus identidades?

¿Es lo mismo ser inmigrante marroquí o ecuatoriano que argentino? ¿Y ser inmigrante argentino "con papeles" o "sin papeles"?

Intentando abordar algunos de los interrogantes formulados más arriba, vale decir que los conceptos de integración social/exclusión social resultan claves dentro del marco teórico para el estudio de las migraciones. Esto porque las 
consecuencias y procesos que los mismos acarrean se relacionan expresamente con una dicotomía que define condiciones desiguales en contextos desiguales, lo que a su vez generará el grado desigual de acceso y disfrute de los bienes y recursos (Kaplan, 1998).

En palabras de Martínez Veiga (1997: 281): "Cuando se habla de exclusión, el referente no es sólo la falta de acceso a bienes y servicios que sirven para satisfacer las necesidades básicas y que sería la base que subyace al concepto de pobreza, sino que también se trata de la justicia, de los derechos sociales y todos los derechos de la ciudadanía. Por lo tanto, hablar de exclusión implica referirse a aquéllos que están fuera del mercado de trabajo, de los derechos sociales e incluso de la cultura".

Efectivamente, se trata de un aspecto determinante, si se tiene en cuenta que el fenómeno migratorio en los países del sur europeo está enmarcado en el contexto de un mercado de trabajo segmentado y precarizado, en el marco de una economía sumergida (informal) extensa, en cuyo ámbito se inserta buena parte de los migrantes "extracomunitarios" que llegan al continente. En este sentido, es posible mencionar a la agricultura, además de la construcción, el trabajo doméstico, la hostelería y la venta ambulante, como los ámbitos donde cada vez, en mayor medida, el mercado de trabajo español incorpora mano de obra inmigrante (Goldberg, 2004b).

Respecto a lo anterior, vale mencionar el hecho de que, entre todos los países integrantes de la UE, España, por ejemplo, es el que registra los índices de paro, siniestralidad laboral y temporalidad más elevados. Dichas condiciones de precariedad laboral, sumadas a la Ley de Extranjería vigente, juegan un papel destacado en las dificultades alrededor del proceso de integración de los inmigrantes en la sociedad española.

Según el Colectivo Ioé-UGT (2001: 59), las políticas basadas en la restricción de la inmigración y el endurecimiento de las medidas de entrada y requisitos de regularización, se traduce en un aumento de los inmigrantes clandestinos que tiende a provocar segmentos diferenciados del mercado de trabajo español determinados por la precariedad.

En términos generales, al inmigrante se lo considera sólo como trabajador, esto es, en su dimensión estrictamente económica, como una mercancía: la mercancía fuerza de trabajo ${ }^{12}$. Las mismas características que los hacen deseables como trabajadores los vuelven indeseables como parte de la sociedad receptora. Este es el sesgo que domina las políticas migratorias españolas desde 1985, acentuándose con la Ley de Extranjería actual por medio de la cual: “(...) el gobierno español declara fuera de la ley a todas las personas que no obtengan previamente los correspondientes permisos de entrada y de trabajo.

12 AI igual que la Ley de 1965 en la por entonces "República Federal de Alemania", la Ley de Extranjería vigente en territorio español se asemeja más a una reglamentación para el reclutamiento de mano de obra que una disposición enmarcada en una política de inmigración. De este modo, actualmente, España, como en ese entonces Alemania (donde muchos de los trabajadores de por entonces eran emigrantes españoles), representa un régimen laboral y político respecto de los trabajadores extranjeros que intenta convertirlos en meros productores de mercancias, reduciendo a las personas a una función estrictamente económica:

"Como hemos visto en el caso de los marroquies en España y de otros colectivos -afirma Martínez Veiga (1997: 239)- (...) existe un prejuicio por parte de personas y agencias (...) de considerar a los inmigrantes como una especie de mercancia a merced de la opresión estatal y de los empleadores". 
De esta situación de ilegalidad se deriva la negación de toda una serie de derechos fundamentales de la persona (reunión, manifestación, asociación, sindicación, huelga), además del acceso a una gran parte de los servicios asistenciales del Estado. Esta privación de derechos, unida a la amenaza de expulsión fulminante del territorio español, comportan un panorama de futuro para la inmigración clandestina que la aproxima bastante a las condiciones de esclavitud (...) creándose bolsas de población completamente marginal que para sobrevivir tendrán que padecer las peores condiciones" (Martínez Fresneda, 2001: 25).

¿El problema, entonces, es que los inmigrantes sean pobres e "ilegales"? ¿O que los pobres e "ilegales" son los inmigrantes? (Goldberg, 2004b).

Ante el riesgo de ser expulsados por encontrarse en situación "irregular", los inmigrantes no tienen en general otra opción real e inmediata que renunciar a dar a conocer sus condiciones de vida, la explotación a la que los someten los empleadores y los actos discriminatorios y, en muchos casos, de corte racistaxenófobo de los que son objeto. Tal como sostiene Wagman (2002), "se trata de que vengan inmigrantes que trabajen barato y duro, pero hay que tenerlos achantados y temerosos. Y para que no se les vea como victimas de la explotación, los prejuicios y la discriminación, qué mejor que crear la percepción social de que son conflictivos, irrespetuosos y peligrosos...".

En el contexto español actual, la construcción de la figura del "inmigrante ilegal" como estereotipo de "delincuente", tiene por objeto situarlo en el centro de las preocupaciones y el temor ciudadano, criminalizarlo como forma dominante de percepción social del fenómeno. De esta manera, la inmigración plantea determinados conflictos socio-políticos, laborales, culturales, morales, religiosos, etc. en la sociedad receptora, que pueden ser interpretados por algunos sectores como una especie de "ataque al cuerpo social, al equilibrio y al orden de la sociedad". Lo diferente, lo extraño, se presenta así como lo inesperado, y a lo inesperado se le opone el miedo (Goldberg, 2004b: 55).

De "intrusos" pasan a ser "delincuentes" debido a que, además de colarse "ilegalmente" en el territorio nacional, se les presenta como que vienen a "usurpar" los bienes escasos de la sociedad (trabajo, sanidad, educación, etc.), $\mathrm{y}$, al mismo tiempo, constituyen "factores de riesgo" que pueden llegar a trastocar los valores, tradiciones y moral dominantes ("democracia", cristianismo, etc. $)^{13}$.

De esta manera, la inmigración como fenómeno histórico-social, se encuentra íntimamente relacionada con el proceso y las situaciones descritas, por medio de las cuales, en las diferentes esferas de la sociedad, se ponen en

13 En torno a las variables contextuales relacionadas con las diferentes identidades interactuantes, resulta indispensable recordar que, entre todos los Estados miembros de la UE, España es el que posee la mayor variabilidad étnico-cultural en su interior. Según el Colectivo loé-UGT (2001: 149), "En el caso de España (...) la historia de los dos últimos siglos podría abordarse como resultado de la tensión existente entre los esfuerzos desarrollados por uniformar el mundo normativo y de valores de la población, y las resistencias a esa homogeneización (...) El resultado es que se lleva a cabo una politica de asimilación a la cultura dominante. Como venia ocurriendo con muchas minorias y movimientos de resistencia del propio pais, (...) el rodillo de las normas y criterios establecidos homogéneamente por el Estado (a través del sistema educativo, los medios de comunicación, el trato de favor a la confesión religiosa mayoritaria las pautas familiares propias, etc.) tiene por efecto discriminar las culturas diferentes". 
práctica una infinidad de mecanismos de exclusión, estigmatización, marginación de individuos que por causa de su "otredad" se transforman en "chivos expiatorios" (Goldberg, 2004b).

\section{IV. ¿POR QUÉ BARCELONA?}

Es importante remarcar el hecho de que la ciudad de Barcelona, como contexto geográfico-socio-cultural, posee unas particularidades que la convierten en un lugar especial, que atrae -como pocos en Europa- a la inmigración argentina $^{14}$. Lo anterior constituye un factor para nada despreciable al momento de indagar motivos, razones y causas (no sólo de índole económica) por las que muchos argentinos han elegido durante 2002-2003 este sitio como preferencial para instalarse en su condición de inmigrantes en España.

En ese sentido, el mayor porcentaje de respuestas de los migrantes argentinos entrevistados se ubica en los factores de tipo socio-político, fundamentalmente vinculados a la accesibilidad y el disfrute respecto a los servicios del Estado y la seguridad social, mismos que, a su vez, identifican con el ejercicio de los derechos y libertades ciudadanas que brinda Barcelona, sobre todo para aquéllos cuya situación está regularizada o poseen la doble ciudadanía.

En lo que se refiere a las variables económicas, los datos del último "Informe de coyuntura económica" publicado por Caixa Catalunya, referido al año 2000 (Fuente: El Mundo, 4/8/04, edición digital) muestran que Cataluña, junto a Madrid y el País Vasco, son las comunidades autónomas de mayor nivel de renta y gasto por habitante de todo el Estado español ${ }^{15}$. En otras palabras, digamos que, sobre todo en Barcelona, como capital de Cataluña, la demanda de trabajo no ha superado aún a la oferta, las condiciones y los salarios son mejores que en otros lugares, se produce excedente, se consume y se redistribuye de manera relativa ${ }^{16}$.

A partir de la estancia de formación e investigación realizada en Génova, Italia, durante 2004, y en base a las entrevistas hechas con algunos de los contados argentinos que residen en la ciudad y con diversas personas autóctonas, no es difícil inferir las preferencias y las ventajas que tiene para los migrantes argentinos Barcelona en comparación con Génova u otra ciudad italiana. Incluso se calcula que en Barcelona residen 60.000 argentinos contabilizados por la Administración como ciudadanos europeos, que poseen la doble ciudadanía, y no tanto española sino, sobre todo, italiana. Por lo tanto, aun aquéllos que podrían ir a Italia con pasaporte de ese país escogen Barcelona debido a las mejores condiciones materiales existentes.

14 No solamente a la actual, sino que incluyo a las otras dos anteriores (dictadura militar e hiperinflación alfonsinista-menemismo temprano).

15 Durante el mencionado año, el gasto medio por habitante en Cataluña era de 5.498 euros: un 13,1\% por encima de la media española. Valdria la pena destacar aqui la importancia económica que ha alcanzado el turismo como industria en Barcelona, ciudad donde los extranjeros "bienvenidos" (los llamados "guiris") más dinero gastaron en toda España durante 2001: el 15,85\% del total del Estado.

16 Cierta vez, mi amigo Manolo, gallego, que vive desde pequeño en Barcelona y habla un perfecto catalán (pero sigue siendo -y muy- gallego), me hizo una certera interpretación-definición sobre Cataluña y los catalanes. Dijo textualmente: "En Cataluña la riqueza no se comparte. Se reparte...". 
Es decir, que en Barcelona se dan mejores condiciones de inserción sociolaboral e integración social para los nuevos migrantes argentinos que en otras ciudades de Italia. Lo notable de esta situación es que entre los argentinos existe una mayor identificación cultural-ideosincrática con los italianos que con los españoles, en este caso, catalanes. Precisamente, de los colectivos de inmigrantes que se establecieron en Argentina, y reconociendo el proceso de mestizaje biológico-étnico-cultural que se produjo desde la segunda mitad del siglo XIX en adelante en nuestro país, la influencia de la cultura italiana (tomada como un todo, pero reconociendo a su vez su variablidad interna: genoveses, piamonteses, friulanos, del sur, etc.) ha sido notablemente la más pronunciada. Lo anterior se traduce en distintos aspectos del acervo históricocultural argentino, con lo positivo y lo negativo que ello implica: en la cultura alimentaria, en la forma de vivenciar el fútbol, en la corrupción política, en el enquistamiento de las mafias en el Poder, en aquéllo de "la carne es débil", en la gestualización en el habla, etc.

Lo anterior se refleja también en aspectos de la idiosincrasia y la personalidad del argentino (sobre todo del porteño, pero -ojo- no exclusivamente): esa "picardía criolla" que puede ser usada para fines tan poco nobles. Tanta correlación empírica tiene en la realidad todo lo expuesto, que es muy común que en Barcelona a argentinos e italianos se nos confunda.

En cuanto a los argentinos que residen en Génova, una buena parte pertenecen al grupo de exiliados de la úlitma dictadura militar (1976-1983); en menor proporción, es posible encontrar migrantes que llegaron durante la fase de la hiperinflación de 1989-1992; y son los menos aquéllos que forman parte de la nueva y joven migración de 2001 en adelante. No obstante, los migrantes pertenecientes a estos dos últimos grupos comparten un rasgo, trascendental al momento de intentar explicar el porqué de su instalación en Génova: todos poseen la doble ciudadanía italiana y, en su mayoría, cuentan con parientes lígures o genoveses, ya sea en Argentina o en Génova-Liguria, que les han facilitado las condiciones de inserción sociolaboral en destino. Tal es el caso de Marcos P., un marplatense de 29 años que reside en Génova desde octubre de 2002, trabajando en un negocio familiar de insumos para productos de computación. El dueño de la empresa es un tío suyo, hijo del hermano de su abuelo nacido en Génova, quien emigró a principios del siglo XX a la Argentina y allí sigue viviendo hasta nuestros días:

"Estoy acá en Génova porque tengo trabajo seguro con mi tio y gracias a mi abuelo (genovés que vive en Mar del Plata) que le pidió si le hacia el favor de tenerme con él. Vivo en su casa con su familia y trabajo en su negocio, sólo porque soy pariente y tengo los papeles en regla... él lo hace por mi abuelo porque los italianos tienen un sentido de la familia que es muy fuerte. Pero Génova no tiene nada de especial; es para aprovechar esta oportunidad que tengo, laborar unos años, ahorrar en euros y volver a la Argentina con algo de capital para abrir un negocio allá".

Del mismo modo, es posible encontrar residiendo en Génova a argentinos que han ido becados a estudiar un postgrado por seis meses o un año y se han quedado trabajando por un período mayor en esta ciudad. De cualquier mane- 
ra, al ser interrogados sobre su proyecto migratorio, todos han respondido que su objetivo era regresar en el corto plazo a su país de origen.

\section{PERFIL SOCIODEMOGRÁFICO DE LOS NUEVOS MIGRAN- TES ARGENTINOS EN BARCELONA.}

En base a datos del Ministerio del Interior español, hasta enero de 2004 residían en España en condición "regular" 43.347 ciudadanos argentinos (el $2,6 \%$ del total de residentes extranjeros); mientras que el mismo organismo calcula extra-oficialmente en 110.000 los que se encuentran de forma "irregular", situación que convierte al argentino en uno de los colectivos de inmigrantes con mayor número de "sin papeles" en España.

Desde un punto de vista metodológico, vamos a repasar algunos datos cuantitativos sobre Barcelona como unidad de observación amplia, y del distrito de Ciutat Vella como unidad de observación específica. En primer término, resulta más que relevante el hecho de que Barcelona sea la ciudad europea en la que hay más argentinos residiendo: 10.000 son los argentinos empadronados (es decir, contabilizados por la Administración) en Barcelona, y más de 50.000 -en función de distintos cálculos- los que se encuentran viviendo en condición "irregular".

Es decir, que, en Barcelona, se concentra la mitad de los argentinos "sin papeles" que hay en España y, al mismo tiempo, la quinta parte de los argentinos que, según la Dirección Nacional de Migraciones, dejaron el país desde que estalló la crisis de diciembre de 2001. Lo anterior, sin contabilizar el importante número de argentinos que tiene la doble ciudadanía, quienes figuran para la Administración residiendo fundamentalmente como ciudadanos italianos y españoles $^{17}$.

En segundo lugar, a su vez, tal como permite ver el gráfico detallado a continuación, hasta enero de 2003, la población extranjera contabilizada en Barcelona (163.046 personas) representaba el 10,7\% del total de la ciudad, mientras que en el distrito de Ciutat Vella, el 34, 7\% de la población estaba compuesta por residentes extranjeros.

GRÁFICO 1.Porcentaje de extranjeros sobre la población total del distrito de Ciutat Vella y sus barrios

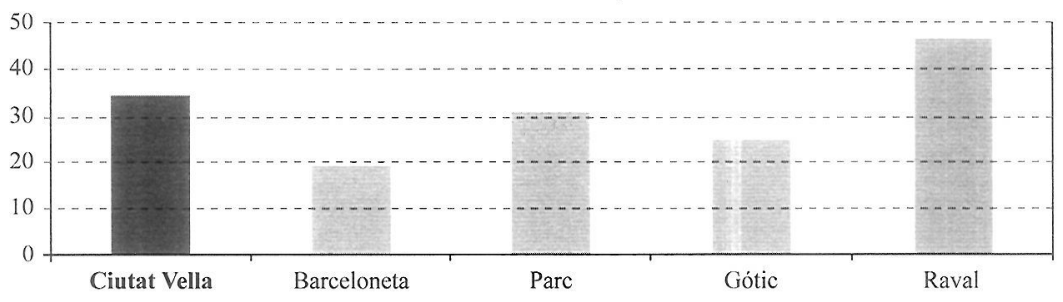

Fuente: Ayuntamiento de Barcelona. Depto. de Estadisticas. Enero 2003

17 Datos empíricamente corroborables mediante distintos procedimientos, algunos incluso del plano cotidiano, como caminar por la Rambla y escuchar hablar argentino, poner un aviso de alquiler de habitación y que el $35 \%$ de los que llamen sean argentinos, llamar por teléfono al Consulado Argentino en Barcelona para pedir un turno, para hacer un trámite, y que lo otorguen recién para dos meses después... 
Es decir, que, en términos de los espacios de interacción de los nuevos migrantes argentinos, entre ellos y respecto a personas pertenecientes a otros colectivos de inmigrantes y a los autóctonos, se trata de uno de los principales contextos donde se producen las complejas relaciones interculturales de la ciudad.

Por otra parte, según datos proporcionados por el Departamento de Estadísticas del Ayuntamiento de Barcelona, el 47\% de los residentes argentinos en la ciudad tiene entre 25 y 39 años. Asimismo, de acuerdo a la misma fuente, casi el $40 \%$ de los argentinos empadronados en la ciudad posee estudios superiores, tal como figura en el cuadro de más abajo. Este hecho ubica al colectivo de inmigrantes argentinos en Barcelona, como el de más alto nivel de estudios entre todos los colectivos de inmigrantes provenientes de países del "Tercer Mundo". El fenómeno citado permite formular dos hipótesis a desarrollar en este trabajo: a) no son los más pobres los que han emigrado de Argentina y b) el argentino es el colectivo de inmigrantes que presenta la mayor diversificación en cuanto a inserción en el mercado de trabajo local respecto a los demás colectivos de inmigrantes del "Tercer Mundo": estudiantes, profesores universitarios, artistas, profesionales, trabajadores por cuenta propia, comerciantes y pequeños empresarios, empleados, entre otros.

TABLA 1. Perfil del colectivo migrante argentino en Barcelona. Enero 2004

\begin{tabular}{|l|c|c|c|}
\hline AÑOS & 2002 & 2003 & 2004 \\
\hline TOTAL POBLACIÓN RESIDENTE ARGENTINA & 4.547 & 9.516 & 11.437 \\
\hline Tasa de crecimiento porcentual* & 81.6 & 109.3 & 20.2 \\
\hline A. Edades & 2002 & 2003 & 2004 \\
\hline Niños de 0 a 14 años & 9.7 & 9.8 & 9.4 \\
Jóvenes de 15 a 24 años & 14.2 & 13.5 & 11.4 \\
Adultos de 25 a 39 años & 47.9 & 54.2 & 55.6 \\
Adultos de 40 a 64 años & 22.4 & 18.6 & 19.4 \\
Mayores de 65 y más años & 5.9 & 4.0 & 4.2 \\
\hline Edad media & 34 & 32 & 33 \\
\hline B. Sexo & 2002 & 2003 & 2004 \\
Hombres & 51.6 & 51 & 50.9 \\
Mujeres & 48.4 & 49 & 49.1 \\
C. Nivel de estudios & 2002 & 2003 & 2004 \\
Primarios & 30.7 & 32.0 & 32.7 \\
Secundarios & 29.9 & 27.0 & 27.5 \\
Superiores & 37.5 & 39.3 & 38.5 \\
\hline D. Año de llegada a Barcelona & 2002 & 2003 & 2004 \\
Menos de 1 año & - & 58.2 & 25.4 \\
Entre 1 y 5 años & - & 35.2 & 69.1 \\
Entre 5 y 15 años & - & 5.4 & 4.7 \\
Más de 15 años & - & 1.1 & 0.9 \\
* Hasta el año 2001, habia 2.504 residentes argentinos. FUENTE: Departament d'Estadistica. Ajuntament BCN.
\end{tabular}

Por último, e intentando establecer una vinculación con lo anterior, vale mencionar un estudio realizado por el Centro de Investigaciones Sociológicas (CIS) de España, en noviembre de 2003, en el que se mostraba que, para el $73,5 \%$ de los españoles consultados, los argentinos constituían los ciudadanos extranjeros que despertaban mayor "simpatía", "proximidad", "similitudes" y "preferencias" (valoraciones que más adelante contrastaremos con los testimonios recogidos en el trabajo de campo), destacándose el "aprecio" y el "inte- 
rés" que despierta en ellos Argentina. En ese sentido, las noticias de lo que allí ocurre son las más seguidas de Sudamérica. Argentina es, de todos los países iberoamericanos, el que consideran "más similar" a España, "más amigo", al que, llegado el caso, querrían ir a vivir, por el que sienten "más simpatía" y en el que invertirían (Fuente: El País, 24/12/03, p. 20).

En suma, se pretende destacar en este planteamiento algunas variables relativas a la especificidad que tiene el fenómeno de la nueva migración argentina dentro del contexto referido.

Dentro del universo de población de estudio que se trata, y con el objeto de aproximarnos a una descripción y poder así analizar en este trabajo las características del proceso de inserción laboral de los nuevos migrantes argentinos en Barcelona, he tomado una muestra de 32 personas. La misma se detalla de la siguiente manera:

- Sexo: 17 hombres, 15 mujeres.

- Franja etárea: a) 15-24 años: 3 hombres, 2 mujeres; b) 25-39 años: 18 hombres, 17 mujeres; c) 40-64 años: 2 hombres.

- Nivel de estudios: a) secundarios: 8 hombres, 5 mujeres; b) superiores: 10 hombres, 9 mujeres.

- Año de llegada a Barcelona: a) menos de 1 año: 3 ; b) de 1 a 5 años: 24; c) de 5 a 15 años: 3 ; d) más de 15 años: 2.

- Ciudad de procedencia: a) Buenos Aires: 14; b) Córdoba: 9; c) Rosario: 4; d) Mar del Plata: 2; e) Mendoza: 2; f) San Juan: 1.

- Ocupación/actividad laboral: a) Estudiantes 3; c) Pequeños empresarios: 2; d) Profesores universitarios: 2; e) Artistas: 4; f) Profesionales autónomos: 8; g) Artesanos: 8; h) Asalariados: 4; i) Desocupados: 1.

- Situación administrativa/migratoria: 1) Residentes "regulares": 19; a) Con permiso de trabajo y residencia en régimen "extracomunitario": 7 ; b) Con residencia en régimen "comunitario" (doble ciudadanía de país de la UE y reagrupación familiar residente "comunitario"): 12. 2) Residentes “irregulares” (sin papeles): 12.

\section{LA INSERCIÓN DE LOS MIGRANTES ARGENTINOS EN EL MERCADO DE TRABAJO LOCAL}

Siguiendo una perspectiva cualitativa, y por medio de la aplicación de una serie de técnicas y procedimientos del trabajo de campo - entre los que se destacan las entrevistas en profundidad y los grupos de discusión- se presentan a continuación algunas (por razones de espacio) de las trayectorias migratorias constitutivas de la muestra tomada para este estudio, mismas que permiten aproximarnos a los distintos aspectos relacionados con los procesos de integración socio-laboral de los nuevos migrantes argentinos en Barcelona.

Entre los factores, motivos, causas y razones económico-laborales principales expresadas por los nuevos migrantes argentinos (pertenecientes a la muestra detallada) para emigrar de nuestro país, se destacan fundamentalmen- 
te dos por encima del resto: 1) el hecho de haber estado trabajando en Argentina en un trabajo que no se correspondía con la calificación de la persona, por un lado, y, 2) que, además, y en muchos casos, en consecuencia, se tratase de un trabajo mal remunerado. Estos dos factores, juntos, suman el $77 \%$ de las respuestas.

Por otro lado, hay que subrayar un dato en relación al mercado de trabajo en destino: el último Boletín de Estadísticas Laborales (BEL), difundido por el Ministerio de Trabajo y Asuntos Sociales de España en agosto de 2004, revela que Argentina es uno de los países sudamericanos que mayor cantidad de mano de obra extranjera contabilizada (es decir, regular) aporta al país. La lista es encabezada por Ecuador (146.299 inmigrantes); le siguen Colombia (75.873), Perú (44.521) y Argentina (28.791).

En ese sentido, es importante apuntar que la situación jurídica-migratoria de los distintos migrantes resulta trascendental desde el momento en que determina, paralelamente, una inserción diferencial en el mercado de trabajo local y una limitación/potenciación concreta en el proceso de adaptación/integración a la sociedad de destino. Todo lo cual impactará, de una u otra forma, en el desarrollo de cada uno de los procesos migratorios individuales, fundamentalmente en relación a las expectativas de partida.

Por último, e intentando establecer una vinculación con lo anterior, vale mencionar un estudio realizado por el Centro de Investigaciones Sociológicas (CIS) de España, en noviembre de 2003, en el que se mostraba que para el $73,5 \%$ de los españoles consultados, los argentinos constituían los ciudadanos extranjeros que despertaban mayor "simpatía", "proximidad", "similitudes" y "preferencias", destacándose el "aprecio" y el "interés" que despierta en ellos Argentina: las noticias de lo que allí ocurre son las más seguidas de Sudamérica; Argentina es, de todos los países iberoamericanos, el que consideran "más similar" a España; "más amigo"; al que, llegado el caso, querrían ir a vivir; por el que sienten "más simpatía"; y en el que invertirían. (Fuente: El País, $24 / 12 / 03$, p. 20)

\section{LA "DOBLE CIUDADANÍA" COMO VEHÍCULO "SEGURO" Y "EFICAZ" DE INSERCIÓN/INTEGRACIÓN}

Solamente con revisar el número de inmigrantes - en su mayoría provenientes del continente europeo- que llegaron para residir en Argentina dentro del período que va de la mitad del siglo XIX a $1930^{18}$, resulta fácil inferir la cantidad de descendientes directos de éstos que hubo en el país.

18 Tomo estas fechas y los datos cuantitativos de Vangelista (1997: 80), quien cifra la cantidad de inmigrantes que llegaron a la Argentina durante el referido periodo en 5.800.000 personas. Toda América recibió inmigrantes por esos tiempos (en mayor número, Estados Unidos); pero ningún país del continente acogió a tantos como la Argentina en relación a su población local. El incremento demográfico experimentado por el pais ha sido notable: en 1825 , la población argentina se reducía a 630.000 personas; en 1850 era de 1.200 .000 ; cincuenta años después, en 1900 había trepado a 4.743.000; y en 1930 alcanzaba los 11.896 .000 habitantes (Fuente: Vangelista, ob. cit.). Por lo tanto, el dicho aquel de que "los argentinos descendemos de los barcos" tiene una parte de verdad histórica con el hecho migratorio europeo: bajo el axioma "gobernar es poblar", los sucesivos gobiernos argentinos desde 1850 en adelante cumplieron la meta de una "Argentina para los 
Dentro del mosaico de colectividades inmigrantes de Argentina, la italiana ha sido la preponderante con un $47 \%$, seguida de la española (32\%). Aquéllos que no renunciaron a su nacionalidad para adquirir la argentina, conservando orgullosos sus papeles de origen (documento, pasaporte, acta de nacimiento, etc.), permitieron que sus hijos y sus nietos nacidos y criados en el país obtuvieran la denominada "doble ciudadanía". ¿Quién no recuerda durante 2001 y 2002 las grandes colas de gente en los consulados italiano y español en Buenos Aires, pasando la noche en la calle para conseguir a primera hora del día siguiente un número y poder iniciar el trámite de la doble ciudadanía?

"Me acuerdo porque hacia un calor infernal. El 22 de diciembre, dos dias después del 'kilombo'19, decidi que era el momento de presentar los papeles que me faltaban para acelerar el trámite y sacarme la ciudadania italiana por parte de mi abuelo. Por suerte, no tardaron mucho en salirme, porque a veces te tardan como un año y medio! Yo esperé sólo unos meses hasta que me llamaron que estaban listos, y a la sema$n a$, el 26 de septiembre del 2002, estaba volando a Barcelona. Me vine para acá porque ya estaba un amigo desde hace un año, laburando (él también tiene el pasaporte italiano), y me dijo que con papeles no era muy dificil conseguir un trabajo bien pagado...".

Luis, 27 años, oriundo de Buenos Aires, trabaja de vendedor [COMERCIAL] EN UNA EMPRESA de Telefonía Móvil de Barcelona.

Al igual que lo que ocurre con muchos otros procesos migratorios de diversos colectivos, nótese en este testimonio la presencia de las cadenas y redes migratorias en la transferencia de información y apoyos materiales que familiares, amigos o paisanos ofrecen a los potenciales migrantes para decidir o, eventualmente, concretar su viaje. Estos mecanismos facilitan el proceso de salida y llegada, pueden financiar en parte el viaje, gestionar documentación, empleo y conseguir vivienda. También son fuente de comunicación de los cambios económicos, sociales y políticos que se producen en la sociedad receptora, que pueden afectar a los potenciales migrantes (Goldberg y Pedone, 2000).

En algunos casos, como el de Susana, diseñadora gráfica nacida en Buenos Aires hace 30 años, la decisión y posterior materialización de venir a Barcelona -hace dos años- estuvo determinada directamente por la presencia de familiares cercanos, además de la posesión del pasaporte español:

"Cuando sentí que ya no se podia estar más en Argentina, empecé a armar la cadena de familiares gallegos por parte de mi vieja. Y resulta que una prima (que no conocia personalmente) estaba estudiando en Barcelona; la llamé por teléfono y ella me dijo que me viniera, y me ofreció una habitación en un piso de alquiler. Además, me contactó con gente que trabajaba en diseño y a las dos semanas empecé a trabajar

europeos"; así como otra parte de verdad negada: con el genocidio de los pueblos indigenas, primeros habitantes de aquellas tierras, perpetrado por la clase dirigente de la época.

19 Se refiere al estallido social del 20 de diciembre de 2001 que desembocó en la huida del entonces presidente De la Rúa, luego de una violenta represión policial contra los manifestantes que protestaban contra el gobierno, sumada al asesinato de 35 personas perpetuados por grupos parapoliciales en distintos puntos del pais. 
como diseñadora en una empresa. Gano bien, no me quejo, pero a nivel laburo me gustaba más lo que hacía en Buenos Aires..."

\section{VIII.TÁCTICAS Y ESTRATEGIAS DE LOS "SIN PAPELES" AR- GENTINOS FRENTE A LOS OBSTÁCULOS DE LA LEY DE EXTRANJERÍA}

\subsection{La "vía" del matrimonio}

Una encuesta de febrero de 2001 elaborada por el Centro de Investigaciones Sociológicas (CIS) arrojaba el siguiente dato: el $27 \%$ de los españoles encuestados confesó que le preocuparía que su hija se casara con un marroquí (llamados despectivamente "moros"). Del lado opuesto, basta con remitirse al otro estudio que se menciona más arriba o bien observar la actitud de la población autóctona marcadamente diferenciada respecto a los migrantes argentinos, para inferir que no todos los inmigrantes son tratados de la misma manera. En efecto, para el imaginario social de buena parte de los españoles, los argentinos aparecemos como más "cercanos", aceptados o próximos física, histórica y culturalmente que los marroquíes. Dicha representación social se relaciona con el vínculo histórico (entre "sobrevivir o morir en el intento") que une a España y Argentina ${ }^{20}$, a la vez que deja entrever los prejuicios existentes entre la población autóctona -alimentados por una buena cuota de ignorancia, ambos elementos fundamentales para el desarrollo del racismo y la xenofobia-contra los "moros"2!.

En cualquier caso, con o sin el consentimiento de los padres del/de la autóctono/a, la realidad muestra que la vía del matrimonio constituye una de las principales estrategias de regularización, integración e inserción en el mercado de trabajo local utilizada por los nuevos migrantes argentinos en España.

En la muestra utilizada para este trabajo, los argentinos incluidos en este grupo en relación a su situación administrativa-migratoria, se enmarcan dentro de los "regulares", en el ítem "con residencia en régimen "comunitario". Nótese que de los 12 del total en régimen comunitario, 6 poseen la doble ciudadanía y los 6 restantes ( 5 hombres y una mujer) obtuvieron la regularización a través de la "tarjeta comunitaria", por reagrupación familiar de residente "comunitario" (léase matrimonio). Es decir, que constituyen una cantidad apreciable en la muestra $\mathrm{y}$, sin ánimo de hacer una inducción, probablemente también entre el universo de la población de estudio.

20 Principio, continuación, final... la circularidad de la historia... Cinco siglos atrás, españoles desembarcaban en América hambrientos de oro... un siglo atrás, regresaban en barcos hambrientos de comida y de trabajo. Entre 1936 y la década de 1950 muchos españoles volvieron a Argentina escapando de la dictadura franquista... hace ya casi treinta años, algunos argentinos (los que pudieron) cruzaron el charco escapando del terror de otra dictadura.

21 Si de algo vale, al menos en un sentido interpretativo de la historia, es preciso recordar que en España el desprecio y los prejuicios contra los "moros" adquiere dimensiones particulares que hay que tener en cuenta, sobre todo porque algunas siguen vigentes entre grupos de la población española. Al respecto, Colectivo loéUGT (2001: 159) afirma: "(...) en España el fenómeno racista tiene raices históricas profundas ya que des de la antigüedad la peninsula ibérica fue lugar de cruce, de confrontación y también de convivencia entre el sur de Europa y el norte de Africa". 
Dos casos, el de Beatriz por un lado, y el de Lucas por el otro, grafican algunas de las características de la "vía" tratada.

Beatriz se vino a Barcelona en mayo de 2002 con la consigna de "ver qué pasa", cansada de su trabajo de 6 horas diarias como secretaria de un consultorio odontológico en el centro de la ciudad de Buenos Aires. Betty -como la llamaron desde pequeñita- consiguió trabajo en junio como camarera de un bar cercano a la playa de la Barceloneta por la temporada de verano, en el cual el dueño del bar no le exigía "tener papeles". Le pagaba 6 euros la hora y ella hacía 4 horas por la tarde los días de semana y 8 horas los fines de semana. Con lo que ganaba, se alquilaba una habitación en el barrio Gótico de Barcelona " $y$ así iba tirando". A finales de agosto, le comunicaron que no iba a trabajar más allí, sin darle razón o explicación alguna, y, a partir de ese momento, "todo fue una pesadilla de no poder encontrar trabajo porque no tenía papeles. No me queria volver a la Argentina! Estaba tan desesperada, que el Xavi, mi compañero de piso, un día me ofreció que nos casemos asi me daban los papeles. Al principio, me pareció extraño y desconfié, pero después lo consulté con una amiga y me dijo que no significaba nada serio, que él lo hacía de onda para que me dieran los papeles". Así fue, se casaron un mes después en un pueblo del Maresme, cercano a Barcelona y, luego, Beatriz viajó a la Argentina con el pasaporte de su "marido" español para tramitar la documentación correspondiente en el consulado de España en Buenos Aires. Desde su regreso y hasta hoy, trabaja como camarera en una de las sucursales que posee una importante cadena de bar-cafeterías "estilo italiano" en Barcelona.

El otro caso, el de Lucas, tiene un poco más de poesía. Arquitecto cordobés de 29 años, llegó a Barcelona en octubre de 2002 para hacer un postgrado. Comenzó a hacer trabajitos "free lance" para un estudio por los que le pagaban "en negro" y paralelamente se iba desencantando con el programa del postgrado hasta que lo abandonó. Se puso de novio con una arquitecta alemana de Berlín, a quien iba a visitar "cuando podia, más o menos cada dos meses... si no, venía ella a verme a Barcelona". Al año de cumplirse su llegada se le venció la tarjeta-permiso de estudiante ${ }^{22} \mathrm{y}$, al no estar en condiciones de renovarla, quedó en situación "irregular": "No me quería ni mover de Barcelona por miedo a que me agarrara 'la cana' [la policía] y me expulsaran, porque el asunto con esos 'culeados' [cabrones] está cada vez más jodido! Incluso tenía miedo, como paranoia, de salir a tomar algo a la noche por el centro... ¿mirá si me paraban y me pedian documentos; qué hacía? Cuando le dije a Verena (mi novia) que no me animaba a ir a verla por ese tema, ella me dijo por teléfono que no me preocupara, que ella iba a venir a Barcelona a arreglar todo: nos empadronamos en el domicilio de una amiga suya, ella se hizo residente y después de dos meses volvió para que nos casemos... por los papeles, pero desde que volvi de Argentina, que me fui a hacer los papeles, estamos en

22 Sobre todo durante el bienio 2003-2003, la Administración española detectó un alto porcentaje de estudiantes latinoamericanos, entre ellos, una cantidad importante de argentinos, que una vez vencida la tarjeta de estudiante tramitada en el país de origen se quedaban en condición "irregular" en territorio español. A raíz de ello, en 2004 el gobierno del PSOE endurece la normativa para dificultar las condiciones de obtención del mencionado permiso. Para tener una idea de lo referido, hoy dia se les exige a los estudiantes argentinos que vendrán a hacer un postgrado a España por uno o dos años sin beca de estudios, el ingreso de 10.000 euros en una cuenta corriente de un banco español y una declaración notariada del propietario o arrendatario del piso donde vivirá durante el período de estudios, entre otros requisitos. 
pareja, los dos trabajando acá de arquitectos, y alquilando un piso juntos en Sagrada Familia".

\subsection{Migraciones de tipo "golondrina" o de "temporada".}

Una de las tácticas utilizadas por algunos jóvenes migrantes argentinos para eludir los obstáculos de la Ley de Extranjería española es comprar un pasaje en avión por tres meses y venir a Europa aprovechando el permiso de turista sin visado válido para todo el espacio Schengen. El objetivo es juntar la mayor cantidad de dinero posible y regresar con euros al país, haciendo favorecer el tipo de cambio ( 1 euro $=3,90$ pesos argentinos).

Lo anterior es frecuentemente practicado en particular por aquellos que se dedican a producir y/o vender artesanías, bijouterie y otros productos afines de temporada. Y también por algunos artistas de calle "a la gorra".

Vale señalar que este ámbito, el del comercio informal de venta ambulante, constituye uno de los nichos del mercado laboral donde más se insertan en cantidad y variedad los migrantes sudamericanos (tanto en carácter relativamente permanente como temporarios, con o sin papeles). Vendiendo en una playa de las afueras de Barcelona o en un mercadito improvisado en el barrio de Trastevere (Roma), es posible encontrar hombres y mujeres provenientes de Argentina, Brasil, Ecuador, Perú, Uruguay, Bolivia, Colombia y Chile. En este sentido, la venta ambulante puede llegar a ser una alternativa más o menos permanente de subsistencia para los migrantes de determinados colectivos en situación no regularizada. Sin embargo, mientras que para algunos puede constituir un "enganche", la puerta de entrada al sistema, la primera inserción al mercado de trabajo local que mantienen hasta regularizar su situación o conseguir un trabajo más estable; en otros casos, por el contrario, el comercio de venta ambulante es una actividad habitual de subsistencia, formando parte de su estilo de vida, ya sea en su nueva condición de migrantes o desde antes en el país de origen.

"Si pudiste hacer una buena temporada de verano [diciembre-enerofebrero en Argentina] y juntaste la guita para el pasaje, conviene... Yo lo que hago es agarrar un pasaje abierto por tres meses a Barcelona como turista; en Argentina es pleno invierno [junio-julio-agosto] y se labura poco, en cambio ahi es pleno verano. Llevo mis cosas para vender y compro algunas otras por mayor acá que puedan andar en la playa... En Barcelona no me quedo porque no te dejan vender en ningún lado, asi que arranco con un amigo que vive allá para las islas: Mallorca, Menorca, Ibiza, Formentera..., hay mucho turismo europeo, se labura bien, en la calle y pateando la playa. Imaginate, con lo que junto en euros, recupero lo del pasaje y me alcanza para vivir en pesos el resto del año en Argentina!".

WALTER, 25 AÑOS, DE ROSARIO, HACE TREs AÑos QUE VIENE Y VA DE ESA FORMA.

Cabe mencionar que en Barcelona la venta callejera está prohibida por normativa, aunque no constituya un delito en sí. Es decir, no está penalizada como actividad', pero sí algunos de los productos de carácter "ilícito/ilegal" que puede implicar (drogas, CD's piratas, etc.). En este sentido, los vendedores ambulantes (a diferencia de lo que ocurre en Italia, todos inmigrantes extranje- 
ros) están expuestos a una doble acción represiva que incide en sus estrategias de adaptación: por un lado, la falta de papeles; por otro lado, en muchos casos, aún con permisos de residencia en regla y cotizando para la seguridad social, igualmente son perseguidos por la policía. El hecho de ser detenidos puede provocar en su perjuicio desde multas de 150 euros y la incautación de la mercadería, hasta órdenes de expulsión del país.

Por esta causa, muchos de los inmigrantes artesanos, vendedores ambulantes o artistas de calle que residen en Barcelona abandonan la ciudad, sobre todo durante el verano (junio-julio-agosto), y se dirigen a las Islas Baleares, Canarias o el sur de Francia, Italia y Grecia para "hacer la temporada" y luego regresar "a pasar el invierno".

Distinto es el caso de Luis, un mendocino de 36 años que dejó a su familia (esposa y dos hijos pequeños) en Argentina hace dos años para venir a trabajar a Barcelona en una empresa de "soluciones para el hogar" (electricidad, plomería [lampistería], pintura, etc.). A través de un amigo suyo, que estaba trabajando allí desde hace un tiempo, consiguió que la empresa le hiciera los papeles y obtener así el permiso de trabajo. Se trata de un caso de migración "golondrina" como medio de inversión económica familiar, el más frecuente entre los migrantes de países del Tercer Mundo. En cuanto al objetivo de su proyecto migratorio, Luis no tiene dudas:

"Prefiero ganar guita [dinero] acá, sobrevivir sin darme muchos gustos, con lo justo, para poder ahorrar lo más posible, siempre mandando algo de guita a mi familia, hasta que me canse o extrañe demasiado y ahi pegar la vuelta pero con algo en el bolsillo. Así me construyo la casa allá y por ahí, con suerte, me puedo comprar un terrenito para cultivar algo y después venderlo. No sé cuánto más voy a aguantar acá, esto es muy distinto, la gente, todo... Extraño mucho a mis pibes [por los hijos], a mis amigos allá, pero bueno, como dicen acá: «es lo que hay" ".

\subsection{Migrantes de "primera"}

Son una minoría dentro del espectro del colectivo, pero se hacen notar: los argentinos que residen en Barcelona como pequeños propietarios de comercios (bares, tiendas de distintos rubros: ropa, mayoristas y minoristas de bijouterie, comidas, etc.) o empresarios. Se trata mayoritariamente de personas con edades comprendidas entre los 40 y los 64 años que tenían dinero ahorrado en dólares en Argentina (no en el banco, afortunadamente para ellos...) y con ese capital comenzaron a invertir en emprendimientos económicos. Algunos compraron pisos para alquilar las habitaciones; otros, bares en mal estado, casi abandonados, para restaurar y modernizar; los menos, se trajeron la franquicia de alguna marca importante de jeans y ropa de moda o de helados, por ejemplo, en Argentina y abrieron un local en el Borne ${ }^{23}$.

23 Perímetro barrial del distrito de Ciutat Vella que está "más de moda" de la ciudad. En él, se fue produciendo una transformación fetichista-postmoderna reflejada en el estilo de las galerías de arte, bares y tiendas comerciales absolutamente snob y "for export". Tan es asi, que algunos antiguos vecinos del barrio cuelgan pancartas desde sus balcones con leyendas del tipo: "Detrás de una fachada pintada, una finca en ruinas"; o "Barcelona posat guapa per fora, tambe per dintre" ("Barcelona, ponte guapa por fuera [campaña del Ayuntamiento local para la rehabilitación de pisos antiguos del casco viejo], también por dentro"). Es común 
No exclusivamente, pero es probable escuchar de boca de algunos de ellos comentarios racistas o despectivos contra personas pertenecientes a otros colectivos de migrantes en Barcelona (sean "moros", "ecuatos", "perucas", etc.). Por estos y demás motivos es que concentran el odio y la envidia de otros inmigrantes argentinos y sudamericanos, representand, de alguna manera, el estereotipo del "ser nacional argentino", "europeo"24 "soberbio y egocéntrico" que tantos desencuentros nos produjo entre nosotros y respecto a personas de otros países.

Comúnmente se trata de gente con un horizonte conceptual bastante estrecho de "nuevo rico" que ganó y ahorró dinero durante la nefasta década menemista de 1990. Es posible que a muchos de los argentinos que vivimos en Barcelona nos haya tocado alguna vez encontrarnos con alguien (un "compatriota") así. Ante esa situación, hay quien huye, quien ríe irónicamente y quien se indigna (lamentablemente, también quien se identifica...). Esta forma de "ser argentino" (así como la hay de "ser español") se relaciona, fundamentalmente, con la hegemonía de la clase oligárquica "nacional" en el poder desde la colonia en adelante, reproduciendo su moral y sus concepciones, mismas que supo imponer al resto de la sociedad. Por "oligarquía" designo a las familias tradicionales, de raíz hispánica-colonial y católica (fundamentos de la "nacionalidad"), vinculadas a los poderes militares, mismos que, a través del ejercicio de la violencia, deben asegurar la continuidad de la tradición. Y en cuanto a lo nacional, léase entre comillas, puesto que los apellidos de esta clase terrateniente en Argentina son principalmente de origen vasco y británico. La ideología que representa esta clase es aquélla por la cual la Nación viene formándose desde los muy hispánicos y católicos tiempos de la Colonia (los "buenos argentinos"); en contraposición a la chusma inmigrante (europea por aquel entonces), dominada por ideas anarquistas y ateas (Feinmann, ob. cit.: 31).

Posteriormente, durante el desarrollismo peronista (1945-1955), el fenómeno de industrialización generó grandes migraciones internas de trabajadores del campo a las ciudades más importantes (Buenos Aires, Córdoba, Rosario), a quienes desde estos sectores se los empezó a llamar, despectivamente, "cabecitas negras". Veinte años después, la alianza golpista que usurpó los poderes del Estado, integrada por la oligarquía, el imperialismo yanki, la jerarquía de la iglesia católica y los militares, etiquetaba como "rojos", "zurdos", "comunistas", "subversivos", "terroristas" a todo aquel opositor a la dictadura o simplemente «diferente». Diferente en cuanto a ideología, pensamiento, estética, anhelos, gustos..., y, como los diferentes eran muchos y amenazaban el status quo, se los combatió con el terrorismo de Estado, produciendo un genocidio. Así, "subversivo" fue todo lo que atentara contra el "estilo de vida argentino" o contra el "ser nacional" como absolutos indefinibles (Feinmann, ob. cit.: 98). Pasaron otros veinte años para que el racismo y la discriminación en Argentina

encontrarse con argentinos en este barrio, fundamentalmente con aquellos oriundos de la ciudad de Buenos Aires ("porteños") que trabajan en diseño y publicidad, "artistas alternativos", camareros/as con piercings y el pelo teñido de color, disc-jockeys (pinchadiscos) tecno, niñatas ("conchetas"/"nenas bien") patinando en sus rolers, llevando al lado a su perro de raza, etc.

24 En contraposición a "lo indígena" y "lo negro" latinoamericano. Lo "europeo" sería, justamente, su negación (fenotípica y sociocultural) y uno de los elementos diferenciadores "positivos" de "progreso" que posee Argentina respecto a los demás países del continente. 
se trasladen, esta vez, contra los inmigrantes de los países limítrofes más pobres: Bolivia ("bolitas"), Perú ("perucas"), Paraguay ("paraguas"), continuando vigentes -y muy extendidos- hasta nuestros días, como uno de los "males" (es decir, chivo expiatorio) que siguen "provocando" el profundo deterioro de la situación socio-económica y política argentina.

En cuanto a los motivos por los cuales este grupo de personas se marchó del país, según sus propias valoraciones, ha sido debido principalmente a la "delincuencia" y "porque no se podía vivir más en Argentina":

"Salís a la calle y te 'chorean' [roban] a vos, el auto, la casa... no podés tener tu negocio, si te roban todos los dias!". Vinieron a vivir a España/Barcelona porque "acá es más tranquilo, más seguro, podés tener tu negocio y ganar buena 'guita' [dinero]. Además, viste como son 'los gallegos' [los españoles]... la gente acá es más conformista, les falta ambición, son más lentos y eso te permite competir con más posibilidades de lograr el éxito".

Diego, 43 años, de Buenos Aires, residente en Barcelona y propietario de una empresa DISTRIBUIDORA DE PRODUCTOS REGIONALES ARGENTINOS EN ESPAÑA.

\section{REFLEXIONES FINALES}

A partir de 2004, el éxodo de jóvenes argentinos al exterior, en este caso, como migrantes a Barcelona, fue disminuyendo notablemente respecto sobre todo a 2002-2003. Entre las posibles causas de esta tendencia decreciente de la tasa emigratoria pueden mencionarse al menos dos, interactuando en un sentido dialéctico inversamente proporcional al push and pull: de un lado, la mejora relativa de la situación socio-política en la Argentina (o, al menos, una pausa en el empeoramiento), del otro lado, el endurecimiento de las leyes migratorias y los obstáculos para la contratación de trabajadores inmigrantes, el fortalecimiento del accionar policial represivo contra los "sin papeles" y una cierta saturación del mercado laboral local en ámbitos donde hace pocos años aún había una amplia oferta para la elevada calificación de algunos jóvenes migrantes:

"Parece increible, pero yo desde hace un año estoy buscando trabajo como diseñadora gráfica, haciendo más o menos 5 entrevistas a la semana, y nada. Asi que tengo que ir haciendo trabajitos para ir tirando. Hasta ahora, laburé haciendo encuestas, como promotora [azafata] en eventos y repartiendo publicidad. Antes eso no pasaba: yo trabajé en una empresa como diseñadora durante un año y medio; pero después no me quisieron renovar el contrato y nunca más conseguí trabajo de lo mio. Deci que como tengo papeles puedo trabajar de otra cosa, sino... ". CRISTINA, 28 AÑos, DISEÑAdORA GRÁFICA, de BUENOS AIRES.

Existe un gran abanico de posibles explicaciones para interpretar el hecho de que jóvenes como Cristina elijan quedarse en una ciudad como Barcelona, trabajando en cualquier otra cosa menos en lo suyo, sin pensar por el momento en volver a la Argentina. En este caso, el motivo principal es la diferencia salarial sujeta al tipo de cambio: aun trabajando como encuestadora (y teniendo resuelto por el momento el problema de la vivienda, claro está), Cristina gana 
casi cuatro veces más de lo que ganaría en Buenos Aires trabajando como diseñadora en un estudio. Esto le permite ahorrar algo de dinero en euros --"a pesar de que en Barcelona se gasta mucho sólo con vivir"- para poder disponer de ellos en caso de necesidad, o bien si decide en algún momento regresar a su país, "volver sin la frente marchita...".

La variedad de respuestas abarca también el plano de lo individual y personal, ya no determinadas por motivos estrictamente ligados a lo socio-económico-laboral. En ese sentido, Barcelona es una ciudad poco hostil y abierta a ese tipo de experiencias, sobre todo para los más jóvenes. Gastón, un rosarino de 24 años, llegó a fines de 2002 para "hacer la experiencia, nueva para mí, de vivir sólo, no con mi familia, independizarme económicamente, conocer gente nueva y distinta, viajar..., después, andá a saber..., puede pasar cualquier cosa, pero la idea es pegar la vuelta".

Un dato interesante para analizar es el que concierne a parejas de argentinos entre 29 y 34 años que vivieron un par de años en Barcelona por distintas razones (trabajo, estudio, estudio y trabajo, etc.) y que, o bien habiendo tenido un hijo recientemente, o a punto de tenerlo, deciden regresar a la Argentina. Me atrevería a decir que en esta franja etérea, y sobre todo en una situación como la descrita, se está produciendo la mayor tasa de retorno de migrantes argentinos en Barcelona.

Por último, hay que mencionar los casos de aquéllos que en Barcelona "encontraron su lugar en el mundo". En general, se trata de migrantes mayoritariamente en situación administrativa "regular", ya sea con permiso de residencia y de trabajo o con doble ciudadanía europea, y con un trabajo estable y bien remunerado. Para ellos, no está contemplado por el momento el retorno. Viajan a Argentina como turistas (aprovechando las ventajas del tipo de cambio favorable) o para compartir las fiestas de Navidad y Año Nuevo con amigos y familiares. Algunos, en determinados casos, también invierten el dinero en propiedades y microemprendimientos económicos a futuro.

\section{BIBLIOGRAFIA}

CACOPARDO, M.C. (1992) "La emigración potencial de jóvenes italoargentinos", en Estudios Migratorios Latinoamericanos, 22: 453-495.

COLECTIVO IOÉ-UGT (2001) iNo quieren ser menos! Exploración sobre la discriminación laboral de los inmigrantes en España. Madrid: Comisión Ejecutiva Confederal de UGT.

EUROSTAT (2001) Push and pull factors of international migrations. Brussels: Statistics in Forms.

FEINMANN, J.P. (1998) La sangre derramada. Ensayo sobre la violencia política. Buenos Aires: Ariel.

GERCHUNOFF, P. y LLACH, L. (1998) El ciclo de la ilusión y el desencanto. Un siglo de politicas económicas argentinas. Buenos Aires: Ariel/Planeta.

GOLDBERG, A. (2004a) "El proceso de integración sociolaboral de los nuevos migrantes argentinos en España. Condiciones de inserción, percepciones sociales y relaciones interculturales", comunicación presentada en el Convegnio Internazionale "I latinos alla scoperta dell'Europa. Nuove migrazioni e spazi della citadinanza". DISA-Universita degli Studi di Génova-Fondazione Casa America (Génova, 17-18 giugno 2004). 
GOLDBERG, A. (2004b) Ser inmigrante no es una enfermedad. Inmigración, condiciones de vida y de trabajo. El proceso de salud/enfermedad/atención de los migrantes senegaleses en Barcelona. Tesis Doctoral en Antropología Social y Cultural. Departamento de Antropología, Filosofía y Trabajo Social, Universidad Rovira y Virgili.

GOLDBERG, A. (2003) "Inmigración, ciudadanía e identidades en el contexto español actual", comunicación presentada en el IX Encuentro-Debate América Latina ayer y hoy. Relaciones sociales e identidades en América. Departamento de Antropología Social e Historia de América y de Africa, Universidad de Barcelona, 26-28 de noviembre de 2003.

GOLDBERG, A. y PEDONE, C. (2000) Cadenas y redes migratorias internacionales. Aproximación a un análisis comparativo de dos casos: senegaleses en Barcelona y ecuatorianos en Murcia. Tarragona: IV Congreso de CEALC.

GOLDBERG, A. y PEDONE, C. (1999) Reseña crítica: Garcia Canclini, Néstor (1999), La globalización imaginada. Barcelona: Paidós, en Documents d'Anàlisi Geogràfica, Nro. 37 . Universidad Autónoma de Barcelona.

HOLLOWAY, J. (2002) Cambiar el mundo sin tomar el poder. Buenos Aires: Herramienta.

KAPLAN, A. (coord.) (1996) Procesos migratorios y relaciones interétnicas. Zaragoza: VIl Congreso de Antropología Social, Instituto Aragonés de Antropología, Federación de Asociaciones de Antropología del Estado Español.

KAPLAN, A. (1998) De Senegambia a Cataluña. Procesos de aculturación e integración social. Barcelona: Fundación La Caixa.

LO VUOLO, R. (2003) Estrategia económica para la Argentina. Propuestas. Buenos Aires: Ciepp-Siglo XXI Editores Argentina-Fundación OSDE.

MARTÍNEZ FRESNEDA, G. (2001) "Tres leyes del siglo", en Le Monde Diplomatique, Nro. $63: 25$.

MARTINEZ VEIGA, U. (1997) La integración social de los inmigrantes extranjeros en España. Madrid: Trotta.

NOVICK, S. (2004) "Argentina: país receptor? Aproximación a un fenómeno migratorio reciente", en L. Queirolo Palmas (a cura di): Alla scoperta dell'Europa. Nuove Migrazioni dall 'America Latina. Génova: Studi Migrazioni, volúmen monográfico, mayo 2004.

PARRAMÓN, C. (1996) "Campo migratorio: un concepto útil para el análisis de las estrategias migratorias" en A. Kaplan, coord.: Procesos migratorios y Relaciones Interétnicas. Zaragoza: Vll Congreso de Antropología.

RAVENSTEIN (1885) "The laws of migration", en Journal of the Royal Statistical Society, 48.

RECOLONS, L. (2001) "La población inmigrante de origen extranjero y su impacto en las sociedades europeas", en Revista de Fomento Social, 56: 679-694.

Subcomandante Insurgente Marcos (1996) Siete piezas del rompecabezas mundial. México: Ediciones del FZLN.

UNITED NATIONS (2000) Replacement Migration: Is it a Solution to Declining and Ageing population?. New York: UN.

VANGELISTA, CH. (1997) Dal vecchio al movo Continente. L'immigrazione in America Latina. Torino: Paravia scriptorium.

WAGMAN, D. (2002) "Estadística, Delito e Inmigrantes", en edición digital y SOS Racismo: Informe Anual.

WOLF, E. y PATRIARCA, C. (1991) La gran inmigración. Buenos Aires: Sudamericana. 